comparable kind to any reader. To say that it is hard to know to whom to recommend Mr. Percival's discursive jottings, which range from the multiplication of polynomials to the solution of partial differential equations, is not to deny that some of his remarks were worth making. On the other hand, the teacher who expects a protest against the prevalent inaccuracy in presenting the integral of $1 / x$ will be disappointed to find only the usual formula, and inverse circular functions are said to be essentially acute angles.

The one surprising feature of the book is a sixfigure table of $\log \Gamma(x)$, from 1 to 2 at interval 0.001 . There are only two substantial mistakes, and these would be patent in use : against $1 \cdot 255$, for 6854 read 6834 , and against $1 \cdot 529$, for 8274 read 8174. Perhaps, however, the first row would puzzle an inexperienced user, and when the seventh digit of the Smithsonian table from which he was extracting was a 5, Mr. Percival adopted some rule of thumb instead of looking elsewhere for a closer approximation, and fifty entries are at fault by a unit in the last place for this reason.

E. H. N.

\section{Men without Money: the Challenge of Barter and}

Scrip. By Wayne Weishaar and Wayne W.

Parrish. Pp. $x+111$. (New York and London :

G. P. Putnam's Sons, 1933.) 5s. net.

THE severity of the economic depression in the United States has led to the introduction of barter on a considerable scale, and this book provides a vivid record of a remarkable movement in which about a million persons are participating. The simplest form described is that in which commodjties or services are directly exchanged against each other by farmers, dentists, barbers, shopkeepers, doctors, artisans and labourers. Direct barter, however, is limited, since a double coincidence of wants may be lacking. To meet this difficulty, exchanges have been inaugurated to act as clearing houses. One such exchange, for example, found a farmer in Syracuse who was willing to take shirts and shoes for his grain. This was exchanged with a poultryman for eggs and fowls which in turn were traded with restaurants to provide meals for workers engaged in making shirts for the farmer.

Many of the exchanges issue 'scrip' or tokens which circulate as a kind of local money. Certain municipalities have also issued 'scrip' to the unemployed in return for work on the roads. To prevent debasement, this scrip has to be stamped at every transaction, thus building up a fund for its eventual redemption by the municipality.

Sacraments of Simple Folk. By R. R. Marett. Pp. vii +230 . (Oxford: Clarendon Press; London: Oxford University Press, 1933.) $10 s$. net.

In the second series of his lectures on the Gifford foundation delivered in 1932-33, Dr. Marett studies the function of the sacrament in natural religion, that is, as he understands it, in the religion of primitive peoples. A sacrament is defined as "any rite which by way of sanction or positive blessing invests a natural function with a supernatural authority of its own". This definition is tested in the course of the lectures by the study of particular instances among the diverse activities of savage life. Ritual, instead of a deadening, is shown to be a vitalising force, bringing emotion to the support of reason in promoting right action, these terms in this context, naturally, being used in a relative sense.

It will be seen that Dr. Marett's point of view in his analysis of primitive institutions and their ritualistic accompaniments is both psychological and sociological, while he applies a formula to the behaviour of primitive peoples which is equally applicable to that of more advanced civilisations. This, however, is an aspect of his inquiry to which Dr. Marett makes only incidental reference. It should not, however, be overlooked, lest the broader view of anthropological studies be forgotten.

The Progress of Man: a Short Survey of his Evolution, his Customs and his Works. By A. M. Hocart. Pp. xvi +316 . (London: Methuen and Co., Ltd., 1933.) 7s. 6d. net.

"Live man," Mr. Hocart says, "wants to know about his past as a key to his present. The man who does not is dead." He has written what is virtually a survey of the material of anthropological science to satisfy that desire. An enormous amount of ground is covered in a small compass; for he has traced the growth and achievement of man "from the time he can be reckoned as man" down to the present day. Mr. Hocart will have none of the arbitrary divisions between prehistory and history, and between savage and civilised. His treatment of the subject is individual in style and original in method; and be it added, at times provocative. It is not possible to comment here in detail upon the many points upon which his views stimulate thought; but attention must be directed to the emphasis he lays on the psychological and ritualistic element in mechanical invention. His protest against the misuse of 'evolutionary' in the study of technical development is salutary.

Network Synthesis: Synthesis of a Finite FourTerminal Network from its Prescribed Driving. Point Functions and Transfer Function. By Dr. Charles Mason Gewertz. Pp. vi +257 . (London : Baillière, Tindall and Cox, 1933.) 23s.

THis work is an interesting exercise, and its subtitle is accurate. The main title alone, however, is quite misleading, for the reader who goes to this book for a general and comprehensive treatment will find that he must first go elsewhere for the foundations on which the author builds, and in the end he will probably conclude that empiricism is sometimes cheaper than pure reason. 